\title{
Antihomocitrullinated Fibrinogen Antibodies are Specific to Rheumatoid Arthritis and Frequently Bind Citrullinated Proteins/peptides
}

\author{
Mathias Scinocca, David A. Bell, Maud Racapé, Radha Joseph, Gary Shaw, \\ John K. McCormick, Dafna D. Gladman, Janet Pope, Lillian Barra, and Ewa Cairns
}

ABSTRACT. Objective. Anticitrullinated protein/peptide antibodies (ACPA) are implicated in rheumatoid arthritis (RA) pathogenesis and linked to the shared epitope (SE). Citrulline modification is very similar to a different modified amino acid, homocitrulline. We investigated antihomocitrullinated protein/ peptide antibody (AHCPA) specificity for RA, whether ACPA were also able to bind homocitrullinated targets, and whether the SE could accommodate homocitrullinated peptide.

Methods. Homocitrullinated fibrinogen was used to screen sera from patients with RA, psoriatic arthritis, and systemic lupus erythematosus, and healthy subjects for AHCPA using ELISA. Homocitrullination sites on fibrinogen were identified by mass spectrometry. ACPA were affinity-purified using a synthetic citrullinated peptide and tested for binding to homocitrullinated protein/peptide. Inhibition of antihomocitrullinated fibrinogen antibody binding was examined. Homocitrullinated peptide interaction with the SE was studied using computer modeling.

Results. IgG antihomocitrullinated fibrinogen antibodies were found specifically in $49 \%$ of patients with RA. Enrichment of ACPA by affinity purification from 5 patients with RA also enriched AHCPA. Serum AHCPA was inhibited by citrullinated fibrinogen and more significantly by homocitrullinated fibrinogen. Computer modeling indicated that the SE could accommodate a homocitrullinated peptide without steric hindrance. Mass spectrometry identified that $89 / 103$ lysines of fibrinogen could be homocitrullinated, and 5 peptides that could be both citrullinated and homocitrullinated and are predicted to bind the SE.

Conclusion. Antihomocitrullinated fibrinogen antibodies are specific to RA. The presence of AHCPA coincides with ACPA, and AHCPA copurifies with ACPA in affinity purification and is inhibited by citrullinated and homocitrullinated antigens. Thus AHCPA and ACPA are frequently cross-reactive and homocitrullinated proteins/peptides may bind the SE. (First Release Jan 15 2014; J Rheumatol 2014;41:270-9; doi:10.3899/jrheum.130742)

Key Indexing Terms:

RHEUMATOID ARTHRITIS

ANTIBODIES

HOMOCITRULLINATED/CARBAMYLATED ANTIGENS

In autoimmune disease, the posttranslational modification of native proteins can generate novel targets that provoke the immune system. The conversion of arginine in proteins/peptides to citrulline in rheumatoid arthritis (RA) is one example. In individuals with the shared epitope (SE), protein residue arginine to citrulline conversion increases peptide binding affinity to MHC class II molecules, specif- ically in the $\mathrm{P} 4$ binding pocket ${ }^{1}$. The subsequent $\mathrm{T}$ cell immune response to citrullinated peptides, and production of anticitrullinated protein/peptide antibodies (ACPA), is highly specific for RA $(>95 \%)^{2}$. ACPA can occur years before onset ${ }^{3,4,5}$, and some studies show that their presence correlates with disease severity ${ }^{6}$. Monoclonal antibodies targeting citrullinated collagen II can exacerbate disease in
From the Department of Microbiology and Immunology, the Department of Medicine/Rheumatology, the Department of Biochemistry, and the Centre for Human Immunology, Western University, London, Ontario; and the Centre for Prognosis Studies in the Rheumatic Diseases, University Health Network, Toronto Western Hospital, Toronto, Ontario, Canada.

Supported by grants from The Canadian Institutes of Health Research (102817) and The Arthritis Society (RG10/010) to Drs. Cairns and Bell. Dr. Cairns is supported by an award from The Calder Foundation.

$M$. Scinocca has been supported by a graduate studentship award from The Ontario Ministry of Training, Colleges and Universities, and by the Canadian Institutes of Health Research.

M. Scinocca, MSc, Department of Microbiology and Immunology, Western University; D.A. Bell, MD, Department of Medicine/Rheumatology; M. Racapé, PhD, Department of Microbiology and Immunology;
R. Joseph, BMSc, Department of Medicine/Rheumatology; G. Shaw, PhD, Department of Biochemistry; J.K. McCormick, PhD, Centre for Human Immunology, Department of Microbiology and Immunology, Western University; D.D. Gladman, MD, Centre for Prognosis Studies in the Rheumatic Diseases, Toronto Western Research Institute; J.E. Pope, MD, MPH; L. Barra, MD, Department of Medicine/Rheumatology; E. Cairns, PhD, Department of Microbiology and Immunology, Western University, Department of Medicine/Rheumatology, the Centre for Human Immunology.

Address correspondence to E. Cairns, Department of Microbiology and Immunology, Schulich School of Medicine and Dentistry, Western University, Dental Sciences Building, Room 3014, London, Ontario N6A5C1, Canada.E-mail: ewa.cairns@schulich.uwo.ca Accepted for publication October 25, 2013.

Personal non-commercial use only. The Journal of Rheumatology Copyright $@$ 2014 . All rights reserved. 
collagen-induced arthritis ${ }^{7,8,9}$; immunization with citrullinated fibrinogen can cause arthritis in DR4 transgenic ( $\mathrm{Tg}$ ) mice ${ }^{10}$; and passive transfer of human ACPA-positive RA serum $^{11}$ or affinity purified IgG ACPA can cause transient arthritis ${ }^{12}$.

A study showed that antimodified citrulline (AMC) antibodies, which have been used to detect citrullinated proteins/peptides in situ, can also detect the amino acid homocitrulline ${ }^{13}$. Homocitrulline is structurally and chemically very similar to citrulline, with both having the same functional group (ureido group); however, homocitrulline's side chain is larger because of the presence of an additional carbon atom. Whereas citrulline is generated by the enzymatic modification of arginine residues by peptidyl arginine deiminase $(\mathrm{PAD})^{14}$, homocitrulline is generated chemically by the carbamylation reaction of cyanate with the primary amine group of lysine residues ${ }^{15}$. While antibodies that bind chemically carbamylated proteins have been referred to as anti-CarP antibodies ${ }^{16}$, we referred to them as antihomocitrullinated protein/peptide antibodies (AHCPA). The cyanate required for lysine carbamylation can be found in the body from at least 2 sources: the spontaneous dissociation of urea ${ }^{17}$, or from the enzyme myeloperoxidase (MPO), which is active at sites of inflammation. Enzymatic production of cyanate during inflammation can be enhanced by environmental influences through the increase of serum thiocyanate, MPO's preferred substrate, which is converted to cyanate ${ }^{17,18,19,20}$. One such environmental cause is smoking, a well-known risk factor for $\mathrm{RA}^{21}$.

Mydel, et al showed that immunization of some mouse strains with a homocitrullinated filaggrin peptide led to erosive arthritis, and some patients with RA had antibodies that targeted this homocitrullinated peptide ${ }^{22}$. Shi, et al also reported that patients with RA have antibodies that bind to carbamylated fetal calf serum proteins and that these AHCPA did not recognize citrullinated proteins/peptides and predicted joint damage ${ }^{16}$. The same group also reported that $16 \%$ of ACPA-negative patients with RA had AHCPA. More recently they reported that some AHCPA can recognize citrullinated proteins such as fibrinogen ${ }^{23}$ and that they occur in $39 \%$ of patients with arthralgia who later developed RA ${ }^{24}$. AHCPA specificity for RA was not examined.

Because citrullinated fibrinogen (or citrullinated peptides derived from fibrinogen) is a frequent target of $\mathrm{ACPA}^{25}$ and is often found in the joints of patients with $\mathrm{RA}^{26,27}$, we investigated whether homocitrullinated human fibrinogen is also a target of IgG antibodies and is specific for RA. We also investigated the immunologic relationship between anticitrulline and antihomocitrulline antibodies and involvement of the SE in these immune responses.

\section{MATERIALS AND METHODS}

Patients. Sera were obtained from patients with RA ( $\mathrm{n}=84$; Appendix 1), all of whom fulfilled the American College of Rheumatology classification criteria for RA ${ }^{28}$; patients with systemic lupus erythematosus (SLE; $\mathrm{n}=$ 37); and patients with psoriatic arthritis (PsA; n = 10) attending St. Joseph's Health Centre Rheumatology Clinic (London, Ontario, Canada). Additional samples of PsA sera $(n=27)$ were obtained from the Centre for Prognosis Studies in the Rheumatic Diseases (Toronto Western Hospital). More sera $(n=27)$ were obtained from healthy volunteers at Western University (London, Ontario, Canada). Among the patients with RA, 75\% were female and $25 \%$ were male, with a mean age of 59.1 years (range 19-83); among the patients with SLE, $89 \%$ were female and $11 \%$ were male, with a mean age of 53 years (range 25-81); among the patients with PsA, $46 \%$ were female and $54 \%$ were male, with a mean age of 53 years (range 36-82). The proportion of women to men among the healthy volunteers was $63 \%$ to $37 \%$, with a mean age of 45 years (range 22-62). This research study was approved by the Human Ethics Committee of Western University (London, Ontario, Canada) and the University of Toronto (Toronto, Ontario, Canada).

Antigens. These antigens were used for antibody assays and/or ACPA affinity purification: (1) human fibrinogen (CalBiochem) - fibrinogen was used in either its unmodified, citrullinated, or homocitrullinated form; (2) citrullinated JED (CitJED) - a proprietary synthetic cyclic citrullinated peptide (with 9/18 amino acid residues being citrulline) developed by us and previously described ${ }^{29,30}$; and (3) homocitrullinated JED (HomoCitJED) - identical to CitJED with the exception that all 9 citrulline residues were replaced with homocitrulline.

CitJED and HomoCitJED were synthesized at Sick Kids Hospital in Toronto, Ontario, Canada. Proteins and peptides were dissolved in sterile, distilled water or sterile phosphate buffered saline (PBS) with the exception that homocitrullinated JED was dissolved in $7.5 \%$ hydrochloric acid in sterile distilled water.

Modifications of fibrinogen. Human fibrinogen (CalBiochem) was citrullinated as described ${ }^{25}$. Seven units of rabbit skeletal PAD II (Sigma) were used to citrullinate $1 \mathrm{mg}$ of fibrinogen.

Human fibrinogen was homocitrullinated using treatment with $0.1 \mathrm{~m}$ potassium cyanate $(\mathrm{KOCN})$ in $0.15 \mathrm{~m}$ sodium phosphate buffer and incubation at $37^{\circ} \mathrm{C}$ for $24 \mathrm{~h}$. Ten mg of fibrinogen was homocitrullinated in a $5 \mathrm{ml}$ reaction.

To remove excess PAD or KOCN and to concentrate fibrinogen, $100 \mathrm{~K}$ Macrosept columns (Pall Corporation) were used. To confirm citrullination or homocitrullination, gel electrophoresis and mass spectrometry were performed.

Mass spectrometry. To identify in vitro citrullinated and homocitrullinated fibrinogen, the modified human fibrinogen was used in sodium dodecyl sulfate polyacrylamide gel electrophoresis and stained with Coomassie blue. Protein bands were isolated and submitted to the University of Western Ontario Functional Proteomics Facility for tryptic digest as described $^{31}$.

Mass spectrometry was performed on digested and lyophilized fibrinogen peptides by Western University Biological Mass Spectrometry Laboratory. Briefly, samples were reconstituted in $20 \mu 1$ of $0.2 \%$ formic acid with sonication for $15 \mathrm{~min}$. Ten $\mu 1$ of each sample was analyzed using a 60-min liquid chromatography (LC) method. LC separation (5-60\% acetonitrile, $0.1 \%$ formic acid over 30 min gradient) was performed on a Waters nAcquity UPLC (ultra-high-performance LC) using a $25 \mathrm{~cm} \times 75$ $\mu \mathrm{m}$, nanoAcquity UPLC, BEH130 C18, $1.7 \mu \mathrm{m}$, reverse phase column with a suitable trapping column (Waters). Ions were detected in electrospray ionization mass spectrometry-positive ion mode (Q-ToF Ultima Global; Waters) using (data dependent acquisition) mode for tandem mass spectrometry. Data were analyzed using the MASCOT server with the National Center for Biotechnology Information database and the following acceptable modifications: carbamidomethyl (C), oxidation (M), phospho (ST), phospho (Y), and either carbamyl (K) or citrullination (R).

Molecular modeling. There are 3 published radiographic crystallographic structures of peptides bound to the MHC class II DR0401 molecule with

Personal non-commercial use only. The Journal of Rheumatology Copyright @ 2014 . All rights reserved. 
the $\mathrm{SE}^{32,33,34}$. Because there are no existing structures for fibrinogen peptides bound to MHC class II SE, the crystal structure of collagen II peptide 261-273 bound to MHC class II DR0401 (PDB code 2SEB) 32 was used for molecular modeling, which was done by substituting the aspartic acid binding at the P4 position to various rotomers of lysine without changing the backbone atom orientation. The lysine residues were manually edited to homocitrulline using PyMOL software and analyzed in the Swiss-PdbViewer application for steric clashes.

Modified fibrinogen (citrullinated or homocitrullinated) peptide binding to the $\mathrm{SE}$ was predicted using a program written by Hammer, et $a l^{35}$ as described for the prediction of citrullinated peptides binding to the $\mathrm{SE}^{1}$. This relied on the assumption that homocitrulline bound similarly to the SE as citrulline. Briefly, lysine residues (potential homocitrullination sites) were changed to glutamine because its side chain functional group is most similar to homocitrulline (and citrulline). The program then compared each 9 amino acid residue-long peptide to the known consensus binding motif for the MHC class II DR0401 and assigned a score. All peptides with a score of 2 or higher were considered potential SE binders.

ACPA purification. A CitJED affinity column was used to purify ACPA including antibodies to cyclic citrullinated peptides (anti-CCP2). Three mg of CitJED was linked to a $1 \mathrm{ml}$ HiTrap NHS-Activated (GE Healthcare) HP column as per manufacturer's instructions, and antibody purification was performed as described ${ }^{29}$. The fraction with the highest $\mathrm{IgG}$ concentration was used for analyses.

Antibody assays. Human sera (and/or purified ACPA) at a 1:100 or higher dilution were tested for the presence of antibodies to CitJED, HomoCitJED, Cit fibrinogen, and HomoCit fibrinogen using ELISA. All ELISA were performed as described ${ }^{10,25}$.

Antibody inhibition used various amounts of soluble antigen in PBS with tween, $0.1 \%$ bovine serum albumin, which were preincubated with diluted serum for $1 \mathrm{~h}$ at room temperature prior to addition to the ELISA plate coated with homocitrullinated fibrinogen.

Antibodies to HomoCit fibrinogen and the peptides CitJED and HomoCit JED were quantified in arbitrary units $/ \mathrm{ml}(\mathrm{AU} / \mathrm{ml})$ by comparison to a reference serum sample for each antigen. The cutoff value for positive IgG anti-CitJED was $3.5 \mathrm{AU} / \mathrm{ml}$, for anti-HomoCit JED was $18.5 \mathrm{AU} / \mathrm{ml}$, for $\mathrm{IgG}$ anti-HomoCit fibrinogen 3.6 AU/ml, and IgG anti-Cit fibrinogen $2.4 \mathrm{AU} / \mathrm{ml}$. Cutoff values were determined using the mean of normal sera reactivity $+2 \mathrm{SD}$.

$\operatorname{IgG}$ anti-CCP2 antibodies were detected using a commercially available ELISA kit (Euroimmun AG). Total IgG was measured in $\mathrm{mg} / \mathrm{ml}$ using a commercially available ELISA kit (Cedarlane).

Statistical analysis. Mann-Whitney U test in Graphpad Prism V5 software was used to compare binding to homocitrullinated fibrinogen between patients with RA and other groups. $\mathrm{P}<0.05$ was considered significant. One-way ANOVA test with Bonferroni correction was used for statistical analysis of inhibition experiments. $\mathrm{P}<0.017$ for this test was considered significant.

\section{RESULTS}

Occurrence of antihomocitrullinated fibrinogen antibodies in $R A$, or patients with other inflammatory rheumatic diseases, and healthy individuals. We used in vitro carbamylated fibrinogen as a homocitrullinated antigen to determine the presence of antihomocitrullinated fibrinogen antibodies (AHCFA) in sera from patients with RA ( $\mathrm{n}=84$, Appendix $1)$, SLE $(n=37)$, PsA $(n=37)$, and healthy individuals ( $n=$ 27). Serum antibody reactivity was significantly increased

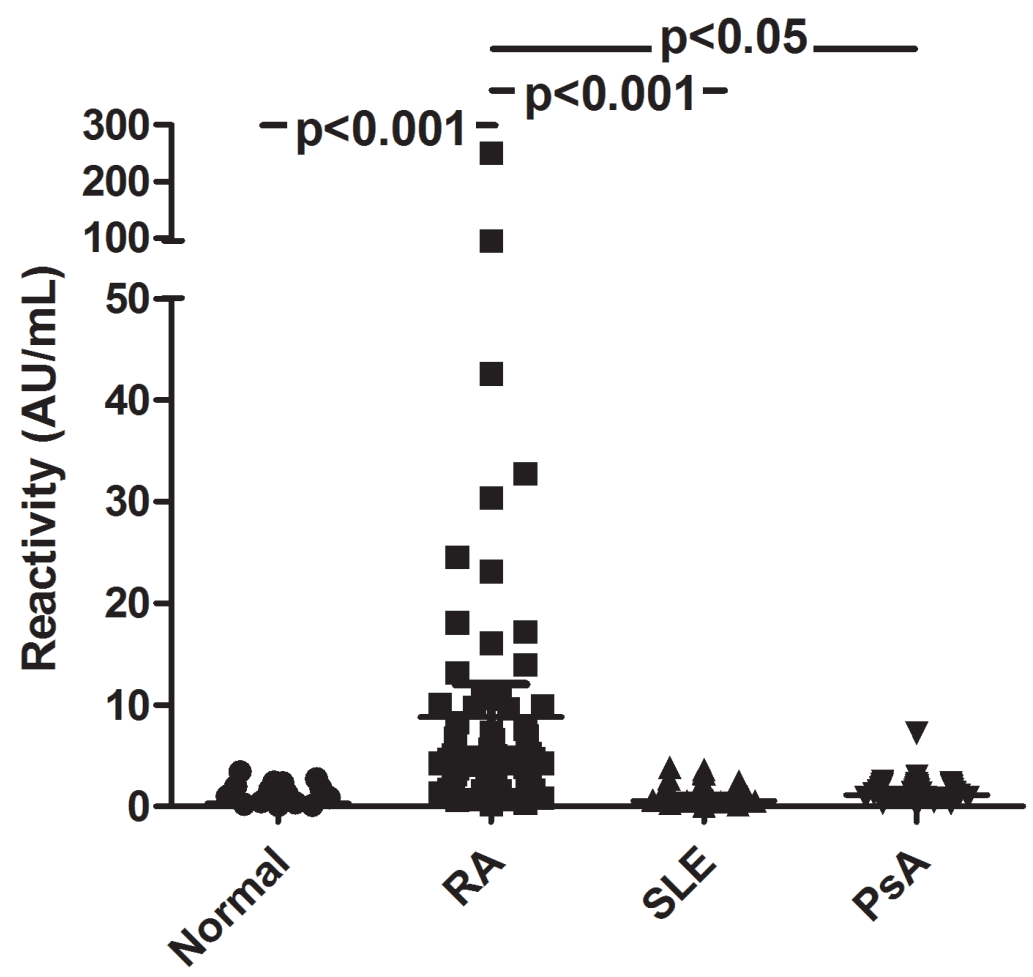

Figure 1. Antibodies to homocitrullinated fibrinogen in healthy subjects $(\mathrm{n}=27)$ and patients with rheumatoid arthritis (RA; $\mathrm{n}=84$ ), systemic lupus erythematosus (SLE; $\mathrm{n}=37$ ), and psoriatic arthritis (PsA; $n=37)$. Antibodies that bind homocitrullinated fibrinogen are specific to RA. Statistical $\mathrm{p}$ values were calculated using the Mann-Whitney U test. 
in RA ( $p<0.05$; Figure 1). Only $5 \%$ of patients with SLE and $3 \%$ of patients with PsA were weakly positive for AHCFA. In our RA cohort that was $88 \%(74 / 84)$ anti-CCP2-positive, AHCFA were detected in 49\% (41/84) of patients. In the sera of patients with RA, 69\% (58/84) had anticitrullinated fibrinogen antibodies (ACFA). AHCFA were not found in any of the 10 patients with RA who were anti-CCP2-negative. Among the patients with RA, 6\% (5/84) had AHCFA but did not have ACFA (Table 1).

Affinity-purified human ACPA can bind homocitrullinated protein/peptide. We next investigated whether ACPA were also able to bind homocitrullinated protein/peptide. ACPA was affinity-purified from the sera of 5 different patients with RA using the CitJED peptide, and antibody reactivity with CCP2, CitJED, HomoCitJED, HomoCit fibrinogen, and Cit fibrinogen was measured in $\mathrm{AU} / \mathrm{mg}$ of $\mathrm{IgG}$ and compared to serum values to determine enrichment of antibody reactivity to these antigens (Table 2). Enrichment (purified ACPA concentration/serum concentration) of CitJED reactivity was seen in all 5 purifications with an average 172 times (range 35-301) increase in concentration (AU/mg of $\operatorname{IgG})$. Co-enrichment of anti-CCP2 antibody reactivity was also observed with an average 94 times (29-242) increase in concentration (relative units/mg of $\mathrm{IgG})$. Importantly, purification of ACPA from all 5 patients with RA also strongly enriched AHCPA, with an average 150 times (54-358) increased antibody reactivity (AU/mg of $\operatorname{IgG}$ ) to HomoCit JED. Anti-HomoCit fibrinogen antibodies were also co-enriched in the 3 patients who had high serum titers, with an average 76 times (11-122) increased concentration following purification with CitJED. Five of 5 patients had co-enrichment of AHCPA (HomoCitJED) with CitJED affinity purification. These experiments therefore indicate that the affinity purification of ACPA also co-purifies AHCPA.

AHCPA are inhibited by citrullinated and homocitrullinated proteins. Confirming that the observed antibodies to HomoCit fibrinogen involved homocitrulline-containing epitopes, serum from 10 different RA patients with AHCFA were inhibited with soluble HomoCit fibrinogen (Figure 2). Inhibition of AHCFA was also observed with Cit fibrinogen in $8 / 10$ patients studied indicative of immunological cross-reactivity (Figure 2A to I). However, at all doses used, Cit fibrinogen was less effective in inhibiting AHCFA binding than HomoCit fibrinogen (Figure 2A). Inhibition of AHCFA with both Cit fibrinogen and HomoCit fibrinogen was variable among individual patients (Figure 2B to I). One of 10 patients also showed inhibition with fibrinogen (Figure 2K).

Human fibrinogen is extensively accessible to both homocitrullination and citrullination, and some of its homocitrullinated peptides are predicted to bind the SE. Because lysine can be found in different regions of proteins than arginine, we sought to investigate which sites of human fibrinogen

Table 1. Summary of human serology findings. Values represent number of individuals (\%) who tested positive.

\begin{tabular}{lcccc}
\hline & RA, $\mathrm{n}=84$ & Healthy, $\mathrm{n}=27$ & SLE, $\mathrm{n}=37$ & PsA, $\mathrm{n}=37$ \\
\hline Anti-CCP2+ & $74(88)$ & $0(0)$ & $2(5)$ & $1(3)$ \\
AHCFA+ & $41(49)$ & $0(0)$ & $2(5)$ & $1(3)$ \\
ACFA+ & $58(69)$ & $0(0)$ & - & - \\
AHCFA+, ACFA+ & $36(43)$ & $0(0)$ & - & - \\
AHCFA-, ACFA+ & $22(26)$ & $0(0)$ & - & - \\
AHCFA+, ACFA- & $5(6)$ & $0(0)$ & - & - \\
& & & & - \\
\hline
\end{tabular}

RA: rheumatoid arthritis; SLE: systemic lupus erythematosus; PsA: psoriatic arthritis; anti-CCP2: anticyclic citrullinated peptide; AHCFA: antihomocitrullinated fibrinogen antibodies; ACFA: anticitrullinated fibrinogen antibodies.

Table 2. Cross-reactivity of human ACPA. Quantification of antibody reactivity in serum and affinity-purified ACPA is reported in units/mg of IgG.

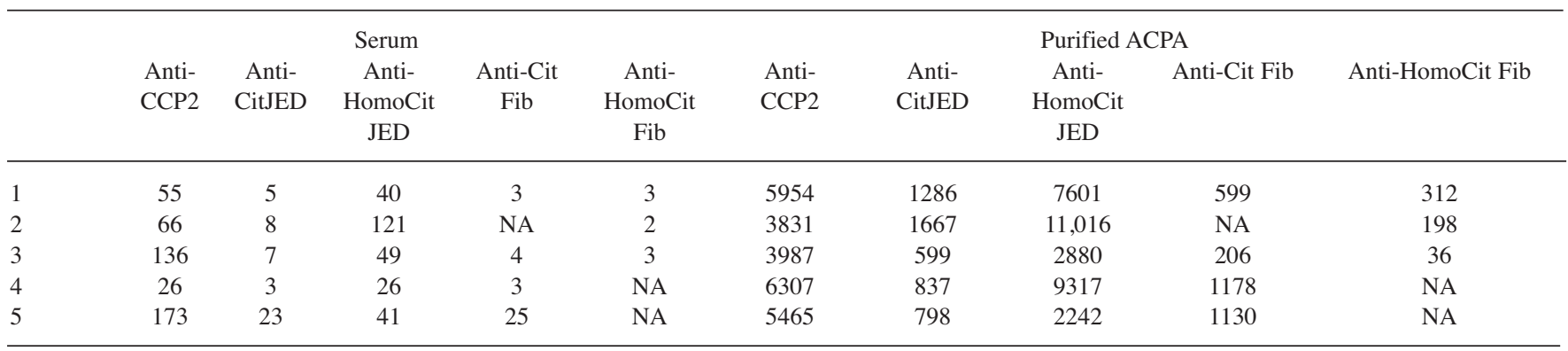

NA: a patient value that was negative or borderline; HomoCit: homocitrullinated; ACPA: anticitrullinated protein/peptide antibodies; anti-CCP2: anticyclic citrullinated peptide.

Personal non-commercial use only. The Journal of Rheumatology Copyright @ 2014 . All rights reserved. 
A

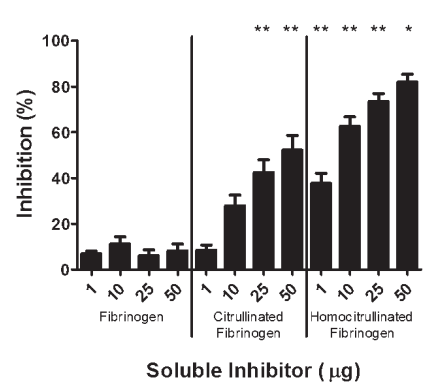

D

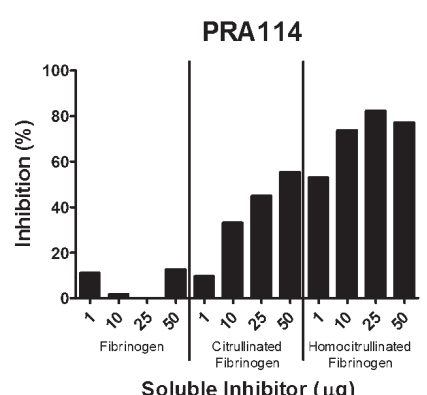

G

PRA122

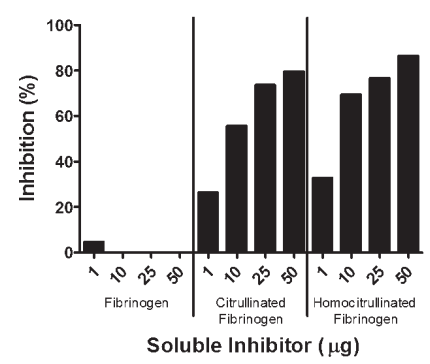

J

PRA115

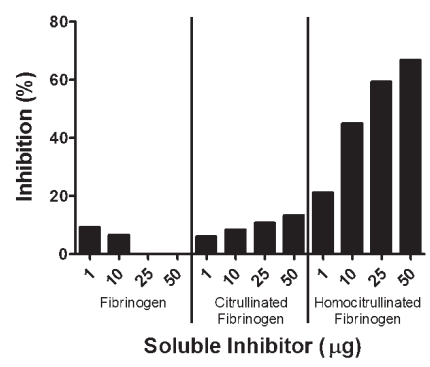

B

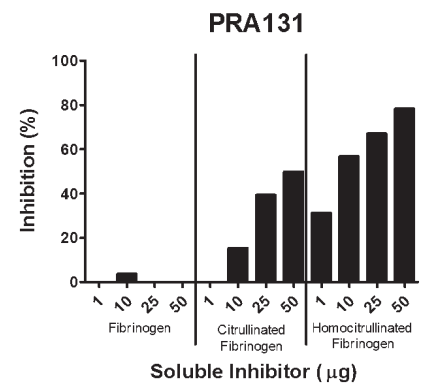

E

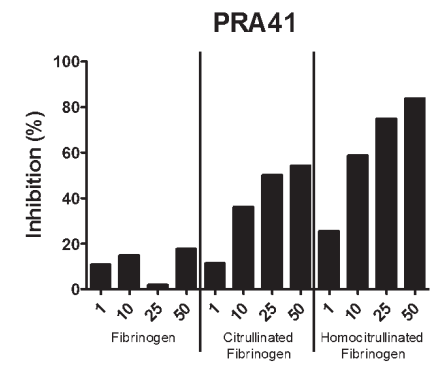

Soluble Inhibitor $(\mu \mathrm{g})$

H

PRA132

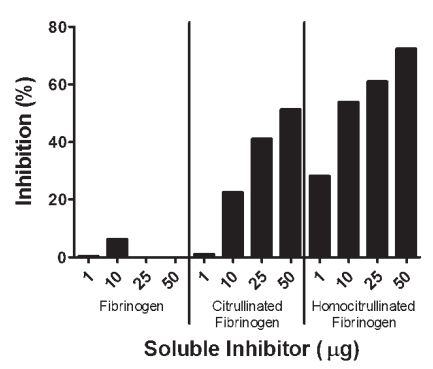

K

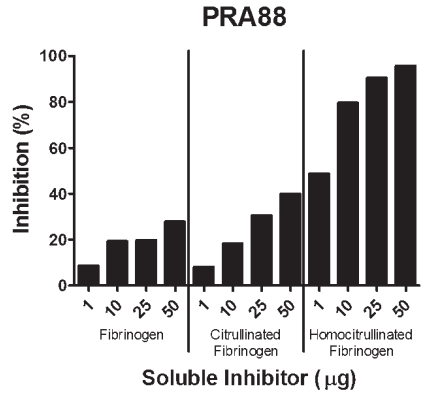

C

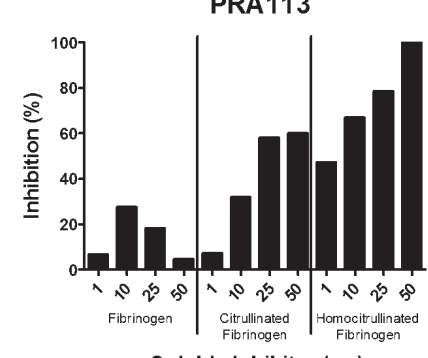

Soluble Inhibitor $(\mu \mathrm{g})$

$\mathbf{F}$

PRA95

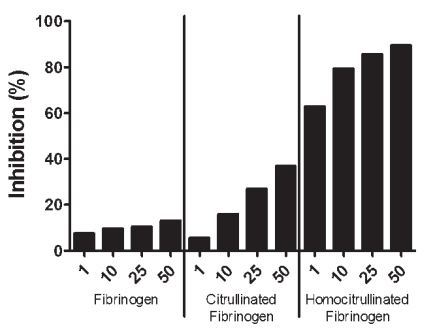

Soluble Inhibitor $(\mu \mathrm{g})$

I

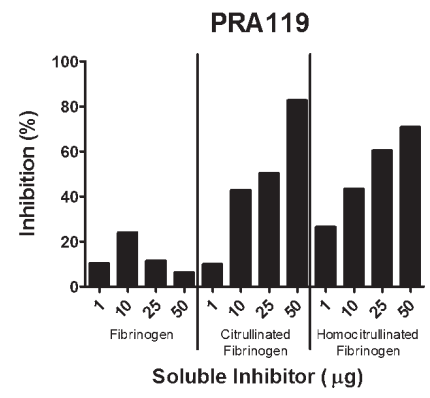

Figure 2. Antibodies that bind homocitrullinated fibrinogen are inhibited by citrullinated and homocitrullinated fibrinogen. A. Pooled inhibition assays of 10 patients with rheumatoid arthritis (RA). Citrullinated fibrinogen inhibition of antihomocitrullinated fibrinogen antibodies is significantly different compared to fibrinogen inhibition at 25 and $50 \mu \mathrm{g}(* * \mathrm{p}<0.001)$ Homocitrullinated fibrinogen inhibition is significantly different compared to unmodified fibrinogen and citrullinated fibrinogen at $1,10,25$, and $50 \mu \mathrm{g}(* * \mathrm{p}<0.001)$. B-K. Inhibition of antihomocitrullinated fibrinogen antibodies for each patient with RA $(n=10)$ with various quantities of either soluble unmodified fibrinogen, soluble citrullinated fibrinogen, or soluble homocitrullinated fibrinogen. 
could be homocitrullinated and potentially serve as a target of AHCPA. Fibrinogen's primary structure includes 103 lysines and 80 arginines. Of the 100 lysines that were analyzed by mass spectrometry, 89 were capable of modification to homocitrulline. Similar analysis of citrullination showed that 56 of the $71(79 \%)$ of arginines that were analyzed could be modified in vitro (Table 3 and Appendix 2 ). Neither citrulline nor homocitrulline were detected with mass spectrometry in our sample of native, unmodified human fibrinogen.

We used the method of Hammer, et $a l^{35}$ to scan 9-mer peptides from homocitrullinated and citrullinated fibrinogen chains to predict their binding to the SE. In a total of 35 peptides (citrullinated or homocitrullinated), we found 5 that could be both citrullinated and homocitrullinated and were predicted to interact with the SE (Table 3 and Appendix 2).

The SE is predicted to accommodate homocitrullinated peptide. To investigate whether the SE could be involved in the immune response to homocitrullinated peptide, we attempted to model this interaction. We examined structural data on peptides bound to the SE+ MHC Class II DR0401 molecule $32,33,34$. The MHC structures were aligned in pairs so that differences in peptide backbone orientation could be observed. Of the 9 residues most important for peptide binding, the first 4 had orientations that were most conserved, with most of the variation being found at the C-terminal end. Because the fourth residue of each core-9 residue peptide interacts with the $\mathrm{P} 4$ binding pocket of the SE, and citrullinated collagen II is a known target of ACPA, we modeled a homocitrulline residue in place of the aspartic acid residue at position $\mathrm{P} 4$ using the 2SEB collagen II 261-273 peptide structure ${ }^{32}$. We found that it was possible to model a homocitrulline residue into the pocket generated by the SE without steric hindrance (Figure 3). Therefore, the SE could accommodate homocitrulline, and homocitrullinated peptide could potentially bind to the SE.

\section{DISCUSSION}

We showed that the protein fibrinogen is extensively accessible to homocitrullination and that homocitrullinated fibrinogen is a target of autoantibodies in a high proportion of patients with RA, in agreement with previous studies ${ }^{16,23}$. These antibodies were not detected in patients with PsA or SLE. We also showed that homocitrullination can generate neo-epitopes on proteins and that homocitrullinated peptides can theoretically be accommodated by the SE. Additionally, we demonstrated that many serum AHCPA bind citrullinated peptides, suggesting that AHCPA and ACPA are frequently cross-reactive. This is highlighted by (1) affinity studies identifying antibodies to CitJED, which showed that both anti-Cit and anti-HomoCit protein/peptide antibodies were recovered and enriched and (2) inhibition studies that showed that AHCPA were usually inhibited by both citrullinated and homocitrullinated fibrinogen. These promiscuous antibodies could have implications on current models of RA pathogenesis because ACPA have been shown to be arthritogenic $^{10,11,12}$, but their relevant in vivo targets have not been identified and their affinity for homocitrullinated peptides has not been investigated. Thus, because parts of the ACPA and AHCPA responses are cross-reactive, synovial inflammation could result from antibody binding to citrullinated antigen or homocitrullinated targets in the synovium.

To date, there are few studies describing protein homocitrullination in immunology $13,16,17,22,23,24$. It is important to study antihomocitrullinated protein/peptide immune responses against proteins that are found in the arthritic joint such as fibrinogen, and thus potentially relevant in disease pathogenesis. The investigations by Shi, et al demonstrated that patients with RA have AHCPA that target homocitrullinated fibrinogen ${ }^{16,23}$. We also used homocitrullinated fibrinogen because (1) ACFA are highly specific for $\mathrm{RA}^{25,27}$; (2) half of ACPA-positive patients with RA are reported to have circulating citrullinated fibrinogen: $\operatorname{IgG}$ antibody complexes ${ }^{36}$; (3) citrullinated fibrinogen is present in inflamed RA joints ${ }^{26,27}$; and (4) immunization with citrul-

Table 3. In vitro homocitrullination and citrullination of fibrinogen.

\begin{tabular}{lcccc}
\hline Modification & $\alpha$ Chain & B Chain & $\gamma$ Chain & Total \\
\hline Homocitrullination & & & & \\
Lysines & 38 & 31 & 34 & 103 \\
Mass spec covered & 37 & 31 & 32 & 100 \\
Homocitrullinated & 33 & 29 & 27 & 89 \\
Predicted to bind the SE & 12 & 13 & 10 & 35 \\
Predicted binders that are also citrullinated & 2 & 3 & 0 & 5 \\
Citrullination & & & & \\
Arginines & 41 & 27 & 11 & 79 \\
Mass spec covered & 35 & 27 & 9 & 71 \\
Citrullinated & 29 & 19 & 7 & 55 \\
\hline
\end{tabular}

SE: shared epitope; spec: spectrometry. 


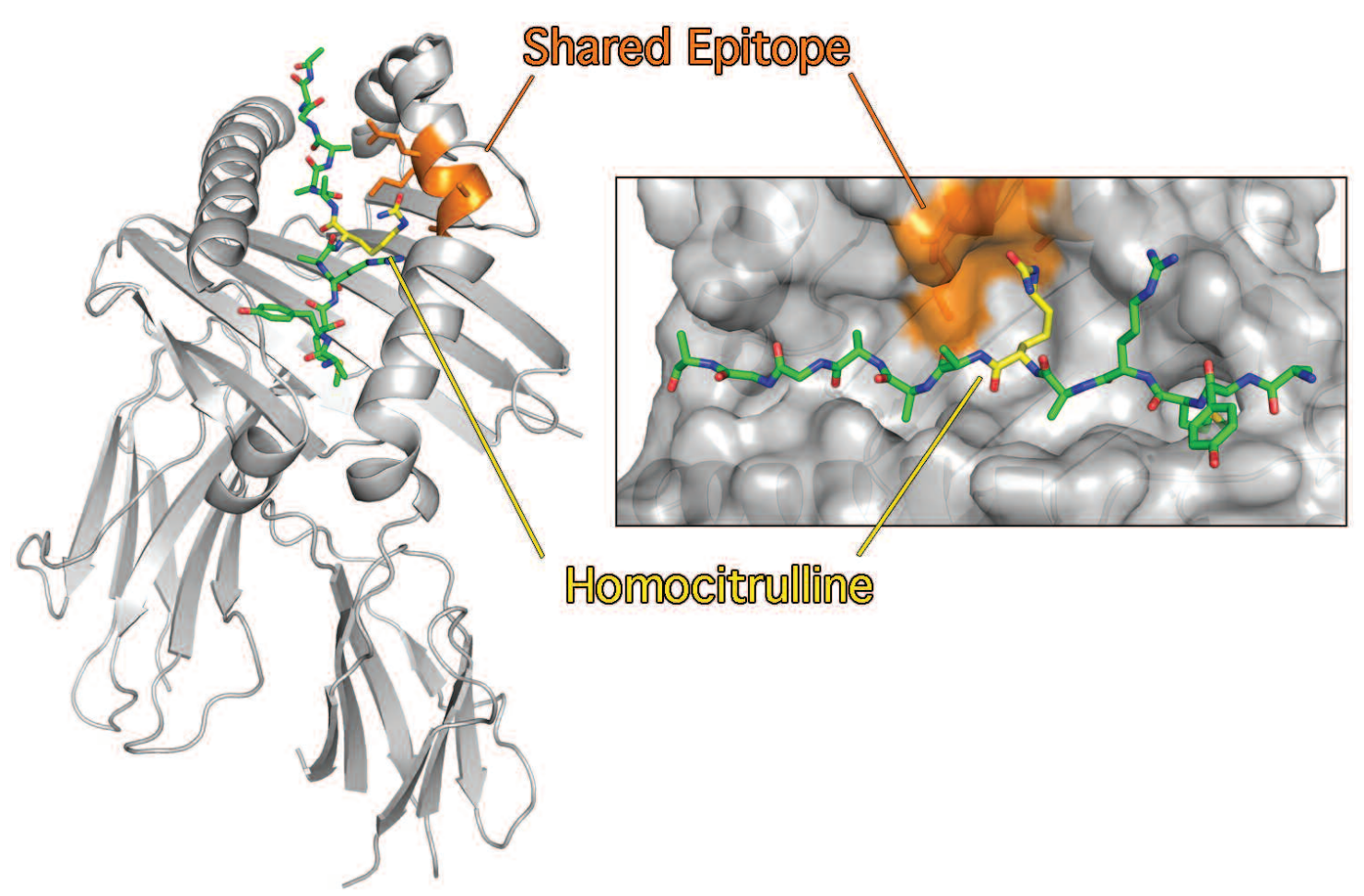

Figure 3. The shared epitope (SE) can accommodate homocitrullinated peptide. Ribbon diagram (left panel) and surface representation (right panel) of collagen II peptide (261-273) binding MHC class II DR0401 (PDB structure 2SEB) after homocitrullination. Collagen peptide is shown in green with homocitrulline in the $\mathrm{P} 4$ position colored yellow (nitrogen atoms are shown in blue and oxygen atoms in red). The MHC class II DR0401 SE (colored orange) accommodates homocitrullinated peptide without steric hindrance.

linated fibrinogen induces arthritis in DR4 Tg mice expressing the $\mathrm{SE}^{10}$.

Our study showed that fibrinogen is also extensively accessible to homocitrullination and that there are in fact substantially more sites for homocitrullination in this molecule compared to citrullination. In agreement with Shi, et al, we confirmed that patients with RA do have antibodies that bind to homocitrullinated regions of fibrinogen ${ }^{23}$. Additionally, we showed that AHCPA were specific to RA because AHCFA were not found in patients with other inflammatory rheumatic conditions. In our study, $<5 \%$ of ACFA-negative patients were positive for AHCFA, which is less than previously reported by Shi, et $a l^{16}$. Our results may differ because they used homocitrullinated fetal calf serum while we used homocitrullinated fibrinogen. In addition, we studied patients with RA who had established disease and low disease activity, whereas the population in Shi, et al were patients with early RA. The existence of anticitrullinated and antihomocitrullinated protein cross-reactive antibodies was first shown by Turunen, et $a l^{13}$ when immunization of rabbits with homocitrullinated albumin triggered ACPA production. Mydel, et al reported the severe arthritis in their mouse model after immunization with homocitrullinated peptide followed by the injection of a citrullinated peptide into the joint ${ }^{22}$. This further suggests cross-reactivity between citrullinated and homocitrullinated peptides. Data provided by Mydel, Turunen, and us supporting citrullinated/homocitrullinated protein/peptide cross-reactivity suggests that, like citrullination, homocitrullination may be involved in the pathogenesis of RA. Homocitrullination could therefore potentially trigger ACPA production and/or generate AHCPA and relevant homocitrullinated antibody targets in the arthritic joint. Cross-reactivity could occur if the B cell Ig receptor in patients with RA recognizes both homocitrullinated and citrullinated protein/peptides. In our inhibition experiments, we showed that AHCFA cross-reactivity to citrullinated and homocitrullinated fibrinogen was not absolute. The higher number of homocitrullinated sites compared to citrullinated sites on fibrinogen could account for the slightly greater inhibitory activity of homocitrullinated versus citrullinated fibrinogen to AHCFA. Alternatively, some AHCFA (and AHCPA) may not bind citrullinated peptides.

Increased homocitrullinated protein/peptide levels were found in the serum and joints of patients with RA by Mydel, et $a l^{22}$. Additionally, the finding that AMC antibody detects in situ homocitrulline residues as well as citrulline ${ }^{13}$ suggests that although some citrullinated proteins have been confirmed in situ by mass spectrometry ${ }^{37,38}$, others identified using AMC may actually have been homocitrullinated. It was also reported that RA patients with erosive disease, specifically, have increased circulating homocitrul-

Personal non-commercial use only. The Journal of Rheumatology Copyright $@$ 2014 . All rights reserved. 
linated peptides and higher levels of AHCPA ${ }^{22}$. We did not investigate the presence of homocitrullinated protein/peptides in vivo or the correlation between disease activity/severity and AHCPA status.

Mydel, et al demonstrated a role for homocitrullinated peptide in sensitization of $\mathrm{T}$ cells, and their data suggested MHC class II dependency in their mouse arthritis model ${ }^{22}$. We have previously shown that ACPA production triggered by citrullination (as opposed to homocitrullination) is linked to the MHC class II SE expression ${ }^{1,10}$. Our molecular modeling suggests that although homocitrulline is larger than citrulline, homocitrullinated peptide, like citrullinated peptide, could be accommodated by the SE. Moreover, when we scanned homocitrullinated or citrullinated fibrinogen we found almost twice as many homocitrullinated sites on fibrinogen as citrullinated sites. Further, some of these homocitrullinated peptides were predicted to bind to the SE. Future investigation of homocitrullinated peptide binding to the SE is warranted to determine its role in the generation of AHCPA in RA.

\section{REFERENCES}

1. Hill JA, Southwood S, Sette A, Jevnikar AM, Bell DA, Cairns E. Cutting edge: the conversion of arginine to citrulline allows for a high-affinity peptide interaction with the rheumatoid arthritis-associated HLA-DRB1*0401 MHC class II molecule. J Immunol 2003;171:538-41.

2. Schellekens GA, Visser H, de Jong BA, van den Hoogen FH, Hazes JM, Breedveld FC, et al. The diagnostic properties of rheumatoid arthritis antibodies recognizing a cyclic citrullinated peptide. Arthritis Rheum 2000;43:155-63.

3. Kurki P, Aho K, Palosuo T, Heliovaara M. Immunopathology of rheumatoid arthritis. Antikeratin antibodies precede the clinical disease. Arthritis Rheum 1992;35:914-7.

4. Rantapää-Dahlqvist S, de Jong BA, Berglin E, Hallmans G, Wadell $\mathrm{G}$, Stenlund $\mathrm{H}$, et al. Antibodies against cyclic citrullinated peptide and $\operatorname{IgA}$ rheumatoid factor predict the development of rheumatoid arthritis. Arthritis Rheum 2003;48:2741-9.

5. Nielen MM, van Schaardenburg D, Reesink HW, van de Stadt RJ, van der Horst-Bruinsma IE, de Koning MH, et al. Specific autoantibodies precede the symptoms of rheumatoid arthritis: a study of serial measurements in blood donors. Arthritis Rheum 2004;50:380-6.

6. Bukhari M, Thomson W, Naseem H, Bunn D, Silman A, Symmons $\mathrm{D}$, et al. The performance of anti-cyclic citrullinated peptide antibodies in predicting the severity of radiologic damage in inflammatory polyarthritis: results from the Norfolk Arthritis Register. Arthritis Rheum 2007;56:2929-35.

7. Kuhn KA, Kulik L, Tomooka B, Braschler KJ, Arend WP, Robinson WH, et al. Antibodies against citrullinated proteins enhance tissue injury in experimental autoimmune arthritis. J Clin Invest 2006;116:961-73

8. Lundberg K, Nijenhuis S, Vossenaar ER, Palmblad K, van Venrooij WJ, Klareskog L, et al. Citrullinated proteins have increased immunogenicity and arthritogenicity and their presence in arthritic joints correlates with disease severity. Arthritis Res Ther 2005;7:R458-67.

9. Burkhardt H, Sehnert B, Bockermann R, Engstrom A, Kalden JR, Holmdahl R. Humoral immune response to citrullinated collagen type II determinants in early rheumatoid arthritis. Eur J Immunol 2005;35:1643-52.
10. Hill JA, Bell DA, Brintnell W, Yue D, Wehrli B, Jevnikar AM, et al. Arthritis induced by posttranslationally modified (citrullinated) fibrinogen in DR4-IE transgenic mice. J Exp Med 2008;205:967-79.

11. Petkova SB, Konstantinov KN, Sproule TJ, Lyons BL, Awwami MA, Roopenian DC. Human antibodies induce arthritis in mice deficient in the low-affinity inhibitory $\mathrm{IgG}$ receptor Fc gamma RIIB. J Exp Med 2006;203:275-80.

12. Brintnell W, Bell DA, Cairns E. The mechanisms underlying arthritogenicity of human anticitrulline antibodies [abstract]. Arthritis Rheum 2009;58 Suppl:S433.

13. Turunen S, Koivula MK, Risteli L, Risteli J. Anticitrulline antibodies can be caused by homocitrulline-containing proteins in rabbits. Arthritis Rheum 2010;62:3345-52.

14. Vossenaar ER, Zendman AJ, van Venrooij WJ, Pruijn GJ. PAD, a growing family of citrullinating enzymes: genes, features and involvement in disease. Bioessays 2003;25:1106-18.

15. Bobb D, Hofstee BH. Gel isoelectric focusing for following the successive carbamylations of amino groups in chymotrypsinogen A. Anal Biochem 1971;40:209-17.

16. Shi J, Knevel R, Suwannalai P, van der Linden MP, Janssen GM, van Veelen PA, et al. Autoantibodies recognizing carbamylated proteins are present in sera of patients with rheumatoid arthritis and predict joint damage. Proc Natl Acad Sci U S A 2011;108:17372-7.

17. Stark GR. Reactions of cyanate with functional groups of proteins. II. Formation, decomposition, and properties of N-carbamylimidazole. Biochemistry 1965;4:588-95.

18. Wang Z, Nicholls SJ, Rodriguez ER, Kummu O, Horkko S, Barnard J, et al. Protein carbamylation links inflammation, smoking, uremia and atherogenesis. Nat Med 2007;13:1176-84.

19. Olea F, Parras P. Determination of serum levels of dietary thiocyanate. J Anal Toxicol 1992;16:258-60.

20. Husgafvel-Pursiainen K, Sorsa M, Engstrom K, Einisto P. Passive smoking at work: biochemical and biological measures of exposure to environmental tobacco smoke. Int Arch Occup Environ Health 1987;59:337-45.

21. Klareskog L, Malmstrom V, Lundberg K, Padyukov L, Alfredsson L. Smoking, citrullination and genetic variability in the immunopathogenesis of rheumatoid arthritis. Semin Immunol 2011;23:92-8.

22. Mydel P, Wang Z, Brisslert M, Hellvard A, Dahlberg LE, Hazen SL, et al. Carbamylation-dependent activation of T cells: a novel mechanism in the pathogenesis of autoimmune arthritis. J Immunol 2010;184:6882-90.

23. Shi J, Willemze A, Janssen GM, van Veelen PA, Drijfhout JW, Cerami A, et al. Recognition of citrullinated and carbamylated proteins by human antibodies: specificity, cross-reactivity and the 'AMC-Senshu' method. Ann Rheum Dis 2013;72:148-50.

24. Shi J, van de Stadt LA, Levarht EW, Huizinga TW, Toes RE, Trouw LA, et al. Anti-carbamylated protein antibodies are present in arthralgia patients and predict the development of rheumatoid arthritis. Arthritis Rheum 2013;65:911-5.

25. Hill JA, Al-Bishri J, Gladman DD, Cairns E, Bell DA. Serum autoantibodies that bind citrullinated fibrinogen are frequently found in patients with rheumatoid arthritis. J Rheumatol 2006;33:2115-9.

26. Raijmakers R, van Beers JJ, El-Azzouny M, Visser NF, Bozic B, Pruijn GJ, et al. Elevated levels of fibrinogen-derived endogenous citrullinated peptides in synovial fluid of rheumatoid arthritis patients. Arthritis Res Ther 2012;14:R114.

27. Masson-Bessière C, Sebbag M, Girbal-Neuhauser E, Nogueira L, Vincent C, Senshu T, et al. The major synovial targets of the rheumatoid arthritis-specific antifilaggrin autoantibodies are deiminated forms of the alpha- and beta-chains of fibrin. J Immunol 2001;166:4177-84.

28. Arnett FC, Edworthy SM, Bloch DA, McShane DJ, Fries JF,

Personal non-commercial use only. The Journal of Rheumatology Copyright @ 2014 . All rights reserved. 
Cooper NS, et al. The American Rheumatism Association 1987 revised criteria for the classification of rheumatoid arthritis. Arthritis Rheum 1988;31:315-24.

29. Ercan A, Cui J, Chatterton DE, Deane KD, Hazen MM, Brintnell $\mathrm{W}$, et al. Aberrant IgG galactosylation precedes disease onset, correlates with disease activity, and is prevalent in autoantibodies in rheumatoid arthritis. Arthritis Rheum 2010;62:2239-48.

30. Hill JA, Cairns E, Bell DA, inventors. Peptides associated with MHC class II molecules involved in autoimmune diseases. US full patent application (US10/548258) filed 2004 Mar 5; published 2007 Dec 20. Canadian full patent application (CA2518187) filed 2005 Sept 20. Patent Treaty Cooperation Application (WO 04/078098) filed 2004 Mar 5 to secure worldwide protection. Europe (EP1603937) published 2005 Dec 14. Japan (JP2007524583) published 2007 Aug 30. Australia (AU4216925) issued 2010.

31. Gyenis L, Duncan JS, Turowec JP, Bretner M, Litchfield DW. Unbiased functional proteomics strategy for protein kinase inhibitor validation and identification of bona fide protein kinase substrates: application to identification of EEF1D as a substrate for CK2. J Proteome Res 2011;10:4887-901.

32. Dessen A, Lawrence CM, Cupo S, Zaller DM, Wiley DC. X-ray crystal structure of HLA-DR4 (DRA*0101, DRB1*0401) complexed with a peptide from human collagen II. Immunity 1997;7:473-81.
33. Hennecke J, Wiley DC. Structure of a complex of the human alpha/beta T cell receptor (TCR) HA1.7, influenza hemagglutinin peptide, and major histocompatibility complex class II molecule, HLA-DR4 (DRA*0101 and DRB1*0401): insight into TCR cross-restriction and alloreactivity. J Exp Med 2002;195:571-81.

34. Yin Y, Li Y, Kerzic MC, Martin R, Mariuzza RA. Structure of a TCR with high affinity for self-antigen reveals basis for escape from negative selection. EMBO J 2011;30:1137-48.

35. Hammer J, Bono E, Gallazzi F, Belunis C, Nagy Z, Sinigaglia F. Precise prediction of major histocompatibility complex class II-peptide interaction based on peptide side chain scanning. J Exp Med 1994;180:2353-8.

36. Zhao X, Okeke NL, Sharpe O, Batliwalla FM, Lee AT, Ho PP, et al. Circulating immune complexes contain citrullinated fibrinogen in rheumatoid arthritis. Arthritis Res Ther 2008;10:R94.

37. Hermansson M, Artemenko K, Ossipova E, Eriksson H, Lengqvist J, Makrygiannakis D, et al. MS analysis of rheumatoid arthritic synovial tissue identifies specific citrullination sites on fibrinogen. Proteomics Clin Appl 2010;4:511-8.

38. Matsuo K, Xiang Y, Nakamura H, Masuko K, Yudoh K, Noyori K, et al. Identification of novel citrullinated autoantigens of synovium in rheumatoid arthritis using a proteomic approach. Arthritis Res Ther 2006;8:R175.

APPENDIX 1. Demographics of study patients with rheumatoid arthritis.

\begin{tabular}{lcc}
\hline Characteristics & Mean & Range \\
\hline Age, yrs & 59.11 & $19-83$ \\
Disease duration, yrs & 9.4 & $0.4-40$ \\
Health Assessment Questionnaire* & 0.96 & $0-2.625$ \\
Swollen joint count & 4.34 & $0-26$ \\
Sex (25\% male, 75\% female) & - & - \\
\hline
\end{tabular}

* The Health Assessment Questionnaire is a validated score of physical function that is a marker of disease severity. Scores range from 0 to 3; scores $>1$ are considered significant dysfunction. 
APPENDIX 2. Homocitrullination and citrullination sites on in vitro modified human fibrinogen as determined by mass spectrometry. Amino acid sequences of fibrinogen. Black Xs represent sites where homocitrulline was detected and black Zs represent sites where citrulline was detected. Pale Rs or Ks represent Arg or Lys, for which no data were obtained. Underlined letters are sites predicted to bind to the shared epitope using algorithm of Hammer, et al $l^{35}$.

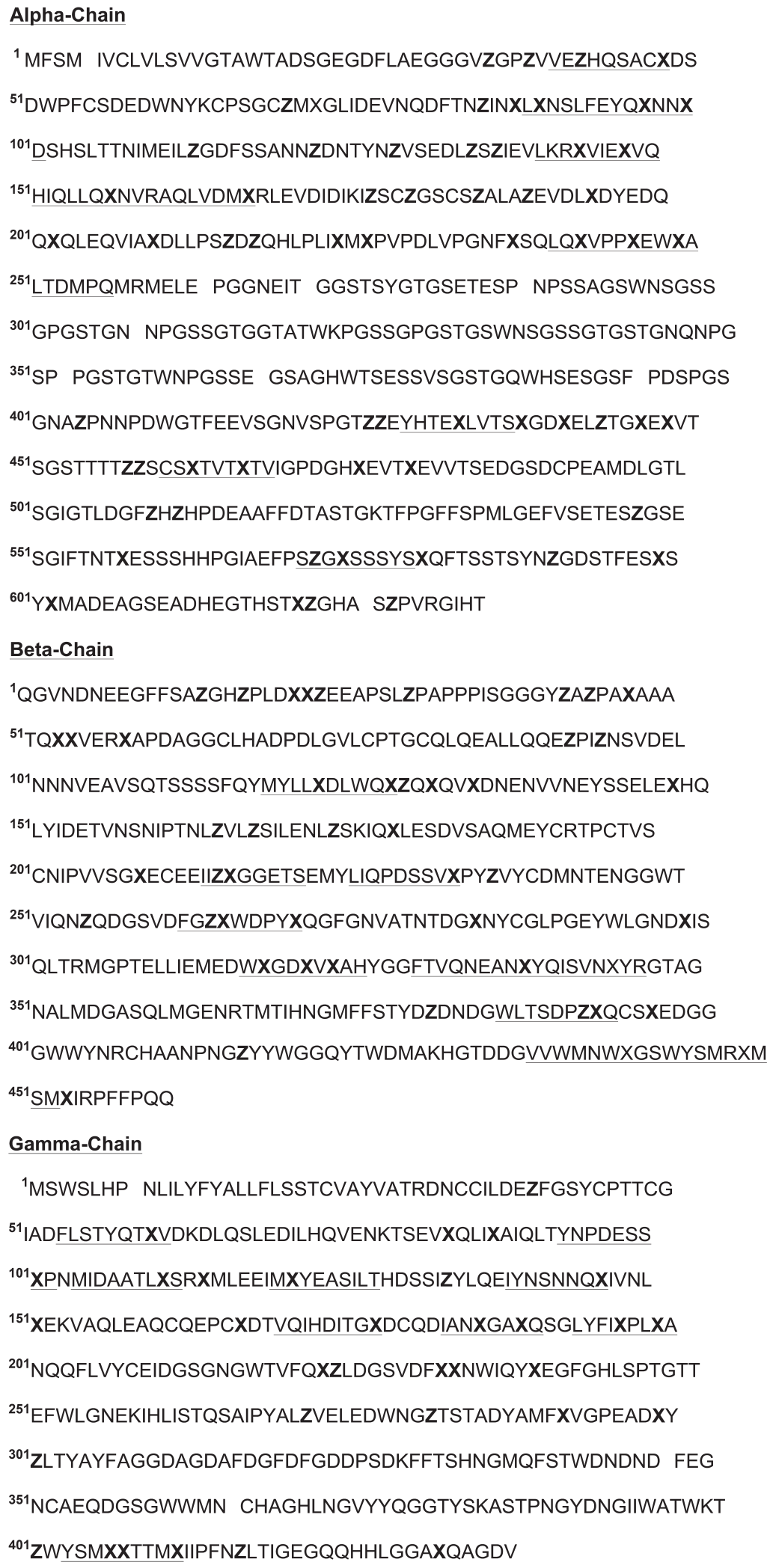

